\title{
Inclusive Educational Practices and Teachers' Skills for Educational Support Services to Students with Learning Disabilities; the Case of Cameroon
}

\author{
Nchia Mary-Judith Youh \\ Faculty of Education, University of Buea, Cameroon \\ Research Consultant: Foundation of Scientific Research, Community Based \\ Rehabilitation and Advocacy on Inclusive Education" (FORCAIE-Cameroon).
}

\begin{abstract}
This conceptual article locates recent developments in inclusive education in a broader discussion about the role of teachers in educating all children more effectively than may have been done in the past. It considers broad as well as contextual issues of achievement, underachievement and participation, and the roles, responsibilities and identities of teachers, as well as the development of their skills and knowledge. In particular it argues for the central role of teachers in promoting inclusion and reducing underachievement, particularly when dealing with children who are perceived as having difficulties in learning. Although there is widespread support for inclusion at a philosophical level, there are concerns that it is difficult to implement for a number of reasons, including that teachers do not know how to do it. This article addresses a series of key issues such as: What is the current international policy context for inclusion? Why are inclusive practices difficult to develop?, How do teachers perceive their roles in supporting inclusion and reducing underachievement?, How might teacher education contribute to the development of inclusive practices?
\end{abstract}

Keywords: Inclusive Educational Practices, Teachers'Skills and Educational Support Services and Learning Disabilities.

\section{INTRODUCTION}

Inclusion of students with special needs is prevalent in many countries. One of many goals of special education is to give students with disabilities the opportunity to participate in the least restrictive environment so that they receive as much education as possible with non-disabled students. There are many strategies and models teachers and school systems are using to ensure special education students are participating within the mainstream classroom setting; however, the inclusion model seems to prove to be the most beneficial in the areas of academic achievement and social interaction. The inclusion model centers on educating students with disabilities in the general education setting along with their non-disabled peers. General education teachers do have concerns about teaching students with learning impairments including lack of training, planning time, and resources so research is essential to demonstrate how the inclusion model can have a positive impact on academic achievement as well as social interaction among students with disabilities. In general, the literature indicates inclusion can be problematic for special needs students. However, the literature indicates with proper training and resources, inclusion can be a practical and effective learning environment.

\section{InClusion: The CurRent InTERnational CONTEXT}

Extending access to education is part of a worldwide agenda. The Education for All (EFA) initiative from the United Nations is an essential element of the Millennium Development Goals, in part because education is seen as being crucial to human development, and also because so many children do not have access to education UNESCO (2005). Across the world, there are many reasons why children do not attend school, including high levels of mobility, social conflict, child labour and exploitation, poverty, gender and disability. Many children are at risk of not attending school, or of receiving a sub-standard education. In some parts of the world, schooling is not available because of a shortage of school places, a lack of quality teachers, or because schools are too far from where children live. Sometimes families choose not to send their children to school because of fears about safety and security, the poor quality of schooling or because of the economic costs. Such costs might 
include school fees, having to buy uniforms, books and materials, and so-called 'opportunity costs' that arise when young people are not economically active because they are in school.

Differences in access to and outcomes from, education depend not only on children's individual circumstances, but also crucially on the country in which they live and in many cases, where they live within that country. In well-schooled, internationally successful countries, such as Scotland, with its long history of compulsory school attendance, such concerns may seem irrelevant, but even here, not all children are in school. And even when they are in school, some children do not have positive experiences of education, nor do they have much to show for their time in school. The so-called 'achievement gap' between those who achieve most and those who achieve least, is a major concern in many countries, including Scotland (OECD, 2007). In response, new initiatives such as More Choices, More Chances (SEED, 2006) have been introduced to tackle this problem. In such countries, the concern is not only about access to schooling, but it is also about ensuring meaningful participation in a system in which achievement and success is available to all (Black Hawkins, Florian $\&$ Rouse, 2007). But why is there such a long tail of underachievement in many countries? Why do educational systems have institutional barriers to participation and achievement? And why do so many teachers think that the problems that some students have in learning should not be their responsibility because they have not been trained to deal with these matters?

Throughout the world, there is an increased awareness of differences in access to and outcomes of education. This has to be understood in the power of education to reduce poverty, to improve the lives of individuals and groups, and to transform societies (e.g. Grubb \& Lazerson, 2004). Developing 'schools for all' is important because schooling is linked to human, economic and social development goals. But at the same time, it is apparent that many school systems perpetuate existing inequalities and intergenerational under-achievement. The reasons for this are complex, but it often relates to deeply embedded attitudes to, and beliefs about, human differences. Nevertheless, dealing with exclusion, marginalization and underachievement is not only the right thing to do; it makes sound economic and social sense. Failure to develop schools capable of educating all children not only leads to an educational underclass, but also a social and economic underclass which has serious consequences for society now and in the future. Therefore, the development of successful inclusive schools, 'schools for all' in which the learning and participation of all children is valued, is an essential task for all countries. It is hardly surprising therefore that tackling under-achievement and increasing inclusion are part of a worldwide agenda. As a result of this interest, a series of national and international initiatives intended to broaden participation for vulnerable groups of children have been enacted. These include the United Nations Education for All initiative (EFA), which was launched in Jomtien, Thailand in 1990, and the Dakar Declaration (UNICEF, 2000).

As previously mentioned, many countries have educational systems that work better for some children than for others. These concerns have become more apparent because of concerns about global competitiveness and the rise of the so-called 'knowledge economy'. In response, many systems have introduced 'standards-based' reforms (McLaughlin \& Rouse, 2000). The process of mainstream education reform began in many countries in the mid 1980s when concerns about economic competitiveness and the efficiency of school systems led to the introduction of marketplace principles in education (Ball, 2006). Such reforms were underpinned by the idea that competition and choice raise standards and accountability. However, it could be argued that competitive environments result in winners and losers and that in such a climate, some children may be seen as more attractive to schools than others. Children who are considered difficult to teach and those who find learning difficult are at increased risk for exclusion when schools operate in a competitive educational marketplace (McLaughlin \& Rouse, 2000, Gillborn and Youdell, 2000). At the same time, but mostly independent of the 'mainstream' reform legislation, many countries have enacted educational policies designed to develop their special education systems or to encourage greater inclusion of children considered to have disabilities or difficulties. Examples can be seen in a series of European Agency for the Development of Special Needs Education (2006) and OECD (2005) initiatives and reports. At the national level, there is the Education (Additional Support for Learning) (Scotland) Act 2004 which points out that a child may require additional support for a variety of reasons. It is clear that such legislation will have an impact not only on the roles of teachers and schools but also significant implications for professionals working in health, social work and other agencies. 
It is important to reiterate that this broader policy context can affect the development of inclusion. Mainstream educational reform initiatives designed to raise standards can be both a facilitator and a barrier to the education of children with learning needs. In many cases these two strands of policy development, inclusion on the one hand and higher standards on the other, do not necessarily make comfortable partners. On the one hand it can be argued that higher standards are good for all children because schools are held accountable for the progress of all learners. On the other hand, it has been argued that the difficulties children experience in learning are a consequence of unresponsive education systems. As a result children are often seen as having 'additional support needs' when there is a discrepancy between what a system of schooling ordinarily provides and what the child needs to support their learning. Thus the professional focus tends to be on what is 'additional to or different from' the provision which is generally available, rather than on what can be done to make schooling more accessible for all (Florian, 2007).

In addition, there are persistent beliefs that when children find learning difficult, it is because there is something wrong with them. The 'classic' special education view assumes that it is not possible to include children with learning difficulties in mainstream settings because their needs are different. The assumption that underpins this view is that it is desirable to group children according to the nature of their abilities, disabilities or difficulties. There are those who claim that because children are different, there will be a diversity of instructional needs. In turn this requires teaching groups to be formed according to these perceived individual characteristics. According to Kaufman et al. (2005), successful teaching of children who are different, requires that they be grouped homogeneously so that special pedagogical approaches can be deployed by teachers who have been trained to use them. It could be argued that when special education is conceptualised in this manner, it is a barrier to the development of inclusion because it absolves the rest of the education system from taking responsibility for all children's learning.

The Republic of Cameroon has enacted various pieces of legislation and signed international conventions aimed at ensuring quality secondary education for all regardless of personal background. Having policies in place is a logical and commendable first step. One of the next logical things to do is to ensure that those charged with implementation possess appropriate profiles in the dimensions of knowledge, skills and professional attitudes. In support of the above view, Swart, Engelbrecht, Eloff and Pettipher (2002), state that in addition to legislation and policies, teachers must be prepared or else inclusive education and quality education for all will not be attained. The government of the Republic of Cameroon is committed to the provision of quality education services, at least at the level of basic and secondary education as reflected in relevant legislation. For example, Law No. 83/13 of July, 1983 relating to the protection of persons with disability, and its Decree of application No. 90/1516 of 26 November, 1990, makes up Cameroon's legal and policy implementation framework relating to the inclusion of children with disabilities. According to the 1983 law, all forms of discrimination against persons with disabilities are prohibited.

Law No. 98/004/of 14 April, 1998 to lay down guidelines for basic, secondary and teacher education in Cameroon, describes teachers as the guarantors of quality education. For teachers to effectively shoulder this responsibility (guarantee quality education) they themselves must be of the best possible quality before and during service. To add, section 35 of 98/004, further states that "the physical and moral integrity of students shall be guaranteed within the educational system. Consequently, all forms of discrimination shall be proscribed" (Tambo, 2000, 2003). Paragraph 9 of the 1996 Constitution of the Republic of Cameroon does not only reinforce the provision of Law No. 98/004 but goes ahead to states that, "the State shall guarantee the child's right to education". The best approach to take as far as inclusive education is concerned would be to equip regular teachers with appropriate knowledge, skills and attitudes in order for them to make the learning environment responsive to students' uniqueness ( $\mathrm{Nel}, 2007)$.

The most recent law enacted is that of 13th April 2010, relating to the Protection and Welfare of Disabled Persons. This law emphasises the prevention of disabilities, re-adaptation, socio-economic and political inclusion of Persons with disabilities (PWDs) and provides for penal measures for violations. Significantly, it provides for the right to an inclusive education for CWDs, and the right to 'special' education for PWDs. In addition, Cameroon is signatory to many international conventions such as the 1989 United Nations (UN) Convention on the Rights of the Child (UNCRC) - which 
guarantees the right to receive quality education without discrimination on any grounds. The 1994 Salamanca Statement and Framework for Action on Special Needs Education, which recommends the inclusion of all children in regular schools regardless of their physical, intellectual, social, emotional, linguistic or other conditions.

What remains a worry is whether teachers in public schools are prepared to shoulder this responsibility. In spite of the fact that teachers are a critical component to creating inclusive classrooms that allow children with disabilities to learn and thrive, their preparation for inclusive education, has not been mentioned in the legislation. To prove the importance of teachers' preparedness for inclusion, The Salamanca Statement and Framework for Action (1994, p. 27) has also identified the knowledge and skills teachers need to possess in order to be effective in providing educational support services to students with disabilities, including those with LD in inclusive settings. Against this backdrop of enabling legislation, as (Titanji, 2008) puts it, Cameroon needs to shift its focus in the direction of issues of implementation. One of the tasks of implementation is to make sure that secondary education teachers are prepared for related challenges. Many experts feel that, in order to provide effective inclusive education for all students, regular teachers need to develop a different set of skills and knowledge than was traditionally required by the profession (Yuh \& Shey, 2008; Schumm \& Vaughn, 1995; and Baker \& Zigmond, 1995).

The research literature suggests that the implementation of inclusion policies has been uneven (Evans \& Lunt, 2002). Whilst there are many success stories to be told about inclusion (Ainscow, 1997; Black-Hawkins, Florian \& Rouse, 2007), there have also been failures and difficulties. Such difficulties have been blamed on a variety of factors including, competing policies that stress competition and ever higher standards, a lack of funding and resources and existing special education practices. It has also been suggested that one of the greatest barriers to the development of inclusion is because most teachers do not have the necessary knowledge, skills and attitudes to carry out this work (Forlin 2001). Therefore, although inclusion is seen as important in most countries, experience tells us that it is difficult to achieve for children with additional support needs for a number of reasons including:

Uncertainty about professional roles and the status of teachers especially those who have responsibilities for additional support needs

A lack of agreement about the nature and usefulness of specialist knowledge

Territorial disputes between professionals associated with certain 'special' practices

Inadequate preparation of teachers and a lack of on-going professional development opportunities.

\section{TEACHERS' VIEWS OF THE INCLUSION TASK}

The current context in which teachers are working is one of rapid change. All areas of education have changed during the past decades, with major changes to the role of teachers, together with the introduction of new approaches to the curriculum and assessment. In addition, the legislation has seen changes in how difficulties in learning are conceptualized from special educational needs to additional support for learning. These changes have involved the development of new understandings about the interactive nature of children's needs and a shift in focus from 'what is wrong with the child?' to 'what does the child need to support their learning?' Such developments have substantially affected the professional identity as well as the roles and responsibilities of many teachers. It also has implications for how teachers are trained and supported in their professional development.

\section{Teachers' Roles And Identities}

The range of teachers who have responsibilities for learning support is wide, as are their professional identities. Primary teachers are more like to see their identity as a class teacher first, then as a learning support teacher second, whereas secondary learning support teachers probably will have made a specific career choice and are more likely to have undertaken additional professional development leading to qualifications. Thus, secondary teachers more commonly describe themselves as 'a learning support teacher' than do primary teachers. Similarly, teachers in special and local authority support services are more likely to have a clear professional identity as 'support teachers'. There is considerable variation in status between learning support teachers in different schools and local authorities. In some schools provision for learning support is marginalised. In other schools, the 
principal teacher (PT) learning support will have significant influence and a high level of management responsibilities, often as a member of the senior management team. Although status is linked to pay and position in the management structure, it is also associated with personal and professional credibility, knowledge, skills and responsibilities.

Differences in professional identity are associated with whether the teachers have specialist qualifications and have made deliberate career choices to work in this field. Many teachers who have responsibility for learning support in primary schools see it as a stage in their career, something they will undertake to get extra experience, or because 'it's my turn'. Several teachers reported that they became interested in the work by accident or because it was available on a part-time basis and it fitted well with other commitments when they returned to teaching. The picture then is complex. Learning support teachers come from a range of different professional backgrounds, their identity and status is influenced by a variety of factors including by where and who they teach, their experiences and their qualifications. Nevertheless, a common theme emerged throughout the focus group discussions with teachers. Most believe that they can make a difference to children's lives. Many said they were motivated by a desire to help vulnerable children, but they were frustrated that not all colleagues shared their commitment to this task.

\section{Theoretical Reflections}

\subsection{Learning Theories Related to Inclusion}

With so many factors that would seem to make inclusive classrooms unproductive, what learning theories might support the idea? Within the school setting, all students are expected to learn academic concepts as well as behavioral skills. Because both of these areas often times are potential barriers for disabled students, they can develop low self-esteem issues which hinder them socially. "These learners, due to their histories of repeated failure at school, are likely to feel as though academic outcomes are beyond their control, thus perceiving themselves as less competent than their peers" (Ntshangase, Mdikana, \& Cronk, 2008). It is important that academic content and social skills are addressed within the classroom.

Albert Bandura developed the social learning theory which states that learning, both cognitive and behavioral, takes place through the observation, modeling, and imitation of others. "The main characteristic of the social learning theory, are the centrality of observational learning, a causal model that involves an environment- person- behavior system, cognitive contributions, and self-efficacy and agency" (Miller, 2011). This theory proposes that academic and behavior modeling takes place through verbal instruction, live modeling by a person, and symbolic modeling through four steps: attention, retention, reproduction, and motivation. Inclusion classes capitalize on this theory because disabled peers can observe their nondisabled peers and their teachers and then imitate them both academically and behaviorally. Social learning theory combined with Freudian learning principles focus on teaching children important real-life social behaviors (Miller, 2011). As mentioned before, advocates for inclusion thought this course of action would help students with disabilities by emerging them into a learning community that mimics a mini society. Through this learning community students with disabilities are able to interact with their peers and develop friendships.

When included in the regular classroom, special needs students have the opportunity to see their peers working habits, and they can model those habits and behaviors to reflect their own. This insight ties into the Freudian theory of identification through observation of learned behavior from the peers around them. Bandura and Walter, who were two other researchers who expanded on the exploration of Sigmund Freud's identification concept of identification through modeling, realized that new behavior can be attained by observation; for example, when a student sees a peer being praised for their hard work, the student learns to try that behavior in hopes of pleasing the teacher and being praised also (Miller, 2011). This plays into the observational theory, where students with special needs can watch the correct behavior and model that desired performance.

\subsection{Observational Learning Theory}

Students with special needs can learn not only desired behaviors from their peers through social interaction, they can also learn academically within their learning community. Children can be the best teachers. Cooperative learning involves social interaction amongst the students, and it is the key 
to educational thinkers such as Piaget and Vygotsky (Slavin, 2009). Using social interaction and active experiences in learning helps children to feed knowledge to one another. These methods also promote social communication skills that children will need to possess as adults. They will need to be able to effectively discuss the various issues that will occur as life progresses. Even students with special needs can offer educational knowledge to their peers; if the students learn that they can teach others and learn from others, and then they will feel a sense of belonging, pride, and responsibility. When students are working together, these students can be paired with slower learner students from time to time. When students work together and are able to engage in discussions on different ideas, then the sky's the limit to what types of knowledge the students can transmit to one another. Peer learning helps students to build effective listening and communication skills (Harding, 2009).

\subsection{Guided Learning Theory}

In addition to social learning and observational learning theories, the zone of proximal development also has implication for inclusive classrooms. According to Lev Vygotsky, the zone of proximal development states that students learn when guided by an adult or when working with more capable peers. "A more competent person collaborates with a child to help him move from where he is now to where he can be with help. This person accomplishes this feat by means of prompts, clues, modeling, explanation, leading questions, discussion, joint participation, encouragement, and control of the child's attention" (Miller, 2011). Students with disabilities can learn from their peers without disabilities as well as with the support of adult guidance to gain a better understanding of the concept being taught. For example, peer tutoring has been found to be effective for students with disabilities (McDuffie, Mastropieri, \& Scruggs, 2009). A second example is when a teacher provides scaffolding. Scaffolding occurs a great learning support is provided at the time new concepts are introduced and the support is slowly taken from the student as he or she masters the content.

All three of these theories discussed describe how learning occurs in the classroom both academically and socially. According to Ntshangase, Mdikana, \& Cronk (2008), "high social interaction is important not only for learners' academic achievement but also for their long-term general well-being and personal development". The zone of proximal development, in conjunction with the social learning theory, should theoretically help explain how students with disabilities progress academically and increase appropriate social interactions with placed within an inclusion classroom.

\section{Concept Definition And Relevance}

\subsection{Importance of Inclusive Education}

The importance of inclusive education cannot be over emphasized. There are many benefits that come with it, both to the students with learning disabilities as well as to the teachers. Its importance to students with disabilities (LD) is evident in areas such as academic development, communication and language development, and physical development. The details of each area are discussed in the section that follows.

\subsection{Inclusion of Students with Learning Disabilities}

The area of Learning disabilities (LD) in special education has attracted so much attention, debate, and research recently. According to Obi (2010) this is because students with learning disabilities look normal to the naked eyes but then embody myriads of disabilities which are only noticeable from their performance in education. That explains why LD is often referred to as hidden disabilities because they do not have outwardly visible signs that easily indicate their presence (Shaywitz, 2003). Even though the term learning disabilities did not emerge until 1960s, the condition had been studied far back in 1800s by experts in the field of medicine, child development, optometry, audiology, psychology, speech and language, and education. This multi-disciplinary approach resulted in diverse descriptions, vague definitions, ambiguous prevalence figures, and conflicting etiologies (Obi, 2010). Many definitions exist regarding the term 'learning disabilities'. In fact, much criticism is leveled against this field because there is a lack of consensus on the definition of 'learning disabilities' (Hamill, Leigh, MacNutt \& Larsen, 1987)

\subsection{Main Characteristics of Students with Learning Disabilities}

- Many characteristics of students with LD abound in literature. The following are a summary of the main characteristics that are common to students with LD: 
- The only characteristic that is shared by all students with learning disabilities is uneven development of academic skills. This category is thus very heterogeneous.

- The most common area in which students with LD have difficulty is reading, which is a problem for approximately $80 \%$ of these students.

- Many students with learning disabilities also have difficulty with oral expression, written expression, and mathematics.

\subsection{Prevalence of Learning Disabilities in Cameroon}

The prevalence of learning disabilities in Cameroon cannot be stated in actual figure. This is because very little research - to the best of this researcher's knowledge -has been carried out in the area of learning disabilities in Cameroon. Therefore statistics are not available to tell the number of persons suffering from learning disabilities. However, relating to the types of disabilities which are dominant in secondary schools in Cameroon, Tchombe (2014), states that the most common of the disabilities in inclusive classrooms are learning disabilities.

\subsection{Provision of Educational Support Services to students with LD}

Research reveals that students with LD benefit a lot when they spend a large proportion of the day in general education classrooms (Salend \& Duhaney, 1999). In time passed, many students with LD were educated in separate settings for the most part of the school day (McLeskey, Henry, \& Axelrod, 1999). However, recent statistics show that most students with LD now spend the greater part of the school day in general education classrooms (McLeskey, Hoppey, Williamson, \& Rentz, 2004). Because of the increasing numbers of students with LD in general education classrooms (Tchome, 2014), several activities are needed to ensure that these students have appropriate supports to succeed in these settings. These supports include, more than anything else, well prepared general education teachers, who are knowledgeable about and skilled in the following areas: adaptation of the curriculum and content, assessment, collaboration, using assistive technology, planning and implementing the individual educational plan (IEP), providing effective instruction for students with LD as well as adapting instruction to meet their specific needs (McLeskey \& Waldron 2002). They further add that to provide adequate ESS to these students in general education classrooms requires school wide change that addresses how schools are organized, how they plan and deliver instruction, and the roles teachers play in meeting students' needs. This is because the problems students with LD have appear difficult to solve by regular teachers using normal teaching methods in inclusive classrooms.

These students therefore need intensive remedial intervention from trained teachers if they are to make progress (Munby, Lock, Hutchinson, Whitehead \& Martin, 1999). Nwazuoke (2008), also concludes that personnel - teacher preparation is a critical factor which planners of the inclusive project must give adequate attention to if the goals of inclusive education has to be realized. There are many ways in which the general curriculum may be adapted and/or modified to meet individual needs of students with disabilities (LD). Some of the ways include reformatting assignments and tests so that they are broken down into more concrete steps, using the task-analysis approach, use of organizers or visual aids, formatting multiple choice and matching tests and assignments differently and limiting choices, providing alternate ways to answer questions for example, oral responses or by using word processors, using methods such as pre-teaching and re-teaching, and a vast array of others (Rosenzweig, 2009).

There is therefore need for general education teachers to be trained to understand and utilize the different types of adaptations that are needed to adjust the curriculum. Gunter, Denny and Venn (2000), have identified nine types of instructional materials adaptation. This include reducing the number of items a student is expected to complete in a given time period; extending the time required to complete tasks and the pace of instruction; level of support which include social/personal support that provide assistance in interacting with others, material supports that help students access the general curriculum, and physical support that help clarify the relationship between a behaviour and its consequences; input modifications adaptations in instruction is delivered to the learner and output modifications change the way the learner respond to instruction. It is clear that teachers without appropriate skills and knowledge to carry out the above curriculum adaptation or modification will 
have difficulties in trying to meet the needs of learners with disabilities especially those with learning disabilities in inclusive settings.

Therefore, to provide ESS to students with LD in inclusive settings is more than picking up a bag of instructional tricks at the schoolroom door or learning to mimic the actions of another educator - even a very good one. Good educational support service providers (teachers) are thinkers and problem solvers. They know when children are not learning and can adjust instruction appropriately; they know how to design and use a variety of assessment techniques - not just paper-and-pencil tests; they know how to work with parents to bring out the best in a child; they know that teams of professional educators can transform schools and expect to go about doing it (Yuen, Westwood \& Wong).

Logsdon (2013), points out that, students with LD tend to learn differently and need instructional practices and educational support to learn effectively. He therefore recommends that teachers should be supported and trained to use ICT especially when presenting concepts in teaching and learning activities to assist the students in speeding up their learning success. It must be pointed out that most regular teachers are not comfortable with the inclusion of students with learning disabilities (LD) in their classrooms. They have fears as to whether they can provide the necessary teaching support these students need with sufficient intensity, frequency and duration (Fuch \& Deshler, 2007; Kauffman, McGee \& Brigham, 2004). It is clear from studies that many mainstream teachers are not particularly eager to take part in inclusion, even if they believe such a system is desirable in principle.

Another reason is because they lack confidence in their own ability to teach students with disabilities in general and learning disabilities in particular, and because they feel and fear that they have not had proper training and that needed professional support for teachers would not be sufficient (Scruggs \& Mastropieri, 1996). Rose (2001, p.147), argues that the teaching methods and practices required for the provision of effective support to students with disabilities are easier to identify but when it comes to implementing them, the teachers cannot. This may be because they have not be shown or trained on how to do it.

Rose (2001), further explains that for teachers to feel more confident to provide support to students with disabilities in their classrooms, they should be equipped during the initial (pre-service) and inservice (continuing professional development-CPD) training what it takes to be able to provide support to these students. According to Pearson and Chambers (2005, p.116), this type of training has been recognized as crucial for developing more inclusive practices. The Salamanca Statement (1994, p. 27) states that adequate pre-service and in-service teacher training is essential if teaching/learning especially that which takes place in inclusive settings has to be improved. Based on this statement, the section below throws more light on what pre-service and in-service inclusive teacher training entails.

\subsection{Pre-service Inclusive Teacher Training}

Pre-service training refers to the training teachers receive before they start to teach. This includes training at teacher training colleges and universities at both the national and regional levels. The kind of preparation and training that teachers need to effectively provide support services to students with learning disabilities in inclusive settings begins at the pre-service level that is, before teachers start teaching. Pre-service teacher training in inclusive education is very critical if teachers are to effectively provide ESS to students with LD in inclusive settings. According to Winter (2006), if preservice teachers lack the appropriate knowledge, skills and attitudes to teach in inclusive settings, the included students especially those with learning disabilities in their future inclusive classrooms will definitely be left with few opportunities to achieve their desired goals.

Stofile and Green (2007), is of the opinion that to prepare general education teachers to provide ESS to all students, including those with disabilities must begin at the pre-service level. Consequently, increased emphasis should be placed on teacher preparation programmes to prepare new teachers for inclusive education (Van Laarhoven, Munk, Lynch, Bosma, \& Rouse, 2007). Experts in the field of education have repeatedly expressed the need for teacher training programmes to include specialized courses and training experiences to prepare general education teachers to teach students with disabilities in their classrooms (Baker \& Zigmond, 1995; Giancreco et al, 1993; Schumm \& Vaughn, 1995). Without any doubt, the introduction of inclusive education to teachers during pre-service training will definitely facilitate the development of positive attitudes in teachers so that they can effectively teach all students including those with learning disabilities in inclusive settings. Taking 
part in a pre-service preparation programme contributes to the broader educational experience of teachers and positively moulds their attitudes towards providing educational support services to students with disabilities in their classroom (Oswald, 2007).

Van Laarhoven et al. (2007), states that a positive attitude or disposition towards students with disabilities is a prerequisite for development of effective strategies in inclusive classrooms. Winter (2006) and Evans (2000, p. 37) assert that it is crucial that teachers have positive attitudes towards learners with disabilities from the start of their profession if they are to effectively provide ESS to them. Abosi (2003), feels that pre-service teacher training in inclusive education is very necessary because it causes changes in attitudes that are rooted in ignorance and superstition. It is based on the above that Li et al. (2010), have suggested that teacher training colleges should concentrate on the issues of teachers' attitudes and self-efficacy so that pre-service teachers are better prepared to meet the challenges of providing ESS to students with learning disabilities in their classrooms.

Another value of pre-service training is that when teachers acquire knowledge, skills and attitudes that are necessary to provide ESS in inclusive settings, before they start teaching, they will know what to do in case problems arise in their classrooms. In support of the above view, Winter (2006, p. 86), states that regular education teachers feel more confident in their ability to provide support services to learners with learning disabilities when they engage in pre-service coursework which has relevance to the needs of all learners especially those with disabilities. Mittler (2000) ends by stating that, to ensure that newly qualified teachers have basic understanding of inclusive teaching, is the best possible investment that can be made towards the successful provision of educational support services to students with disabilities in inclusive classrooms.

\subsection{In-service Inclusive Teacher Training}

In-service teacher training includes professional growth for teachers who are already in the classrooms teaching. In addition to developing the skills of teachers before they start teaching, it is necessary that that those who are already in the field teaching, also acquire the relevant competences required to teach in inclusive settings (Catholic Relief Services, 2010). In-service teacher training in inclusive education is as important as pre-service teacher training. It helps teachers to successfuly teach all students including those with learning disabilities in inclusive settings. Most teachers report that all or most of their preparation to function effectively in inclusive settings was got during inservice training and not during pre-service training. For example, based on the findings of a study carried out by Rojewski and Pollard (1993), 91\% of teachers reported that their pre-service training did not prepare them to meet the education needs of students with disabilities.

This insufficiency of pre-service training has been repeatedly seen as a barrier to creating greater inclusive settings (Sharma et al., 2006). Christopher and Sachs (2004), explain that in-service takes place in "contexts of raising standards of teaching where pre-service programmes are inadequate to produce a sufficient supply of competent novice teachers". Just like the rapid growth in the technological field, inclusive education is equally growing in the same speed and for regular teachers to be relevant in inclusive settings; they must constantly update their knowledge, skills and attitudes. This means that continuous professional development for regular teachers must regularly be organized if teachers are to function effectively in providing educational support services to students with LD in inclusive settings. That is why Myreddi and Narayan (1999), propose that "periodic in-service training programmes should be constantly organized for teachers to keep them abreast world-wide development and to equip them to face the challenges of changing trends in education circus the most recent being that of inclusive education. If teachers do not constantly update their knowledge, skill and attitudes through in-service training, they are likely to become irrelevant in providing educational support services which are necessary to students with disabilities (LD) in inclusive settings.

The importance of in-service inclusive teacher training to regular education teachers cannot be overemphasized. This is so because in time passed, teachers were not trained to teach diverse students in inclusive settings but rather to teach a homogeneous set of students (one-size-fits-all). Recent developments in the field of education require that teachers take care of the needs of all students, including those with disabilities in their classrooms. Oswald (2007), backs this view when he states that "teachers were not required, and therefore not trained, to respond to learner diversity and are currently teaching without the necessary knowledge, skills and dispositions to handle diverse 
learning needs in their classrooms". Winter (2006), feels that teachers resist teaching students with disabilities in their classrooms in most instances because they have not been equipped with the functional knowledge and skills necessary to teach them. Mutepfa and Mpofu (2007), reported occasions that learners with disabilities had to be sent away from schools in Zimbabwe because teachers felt they did not have the appropriate inclusive competences needed to provide support services to them in their classrooms.

Through in-service training programmes, teachers are given the latitude to learn about inclusive practices and also to acquire the inclusive competences they need in order to effectively provide ESS to students with disabilities in their classrooms. When teachers are appropriately trained, learners with disabilities (LD) will no long be regarded as extra load for them to carry. Villa et al. (2003), revealed that in-service training for teachers caused positive changes towards the inclusion of learners with disabilities: teachers moved away from an exclusively didactic teaching approach to cooperative group work for learners, and also developed sensitivity toward learners' individual needs.

In-service training programmes can take different forms such as short courses, long courses, seminars and workshops. In most European countries, supplementary training is considered to be part of inservice training. Guijarro (2000), argues that the training of isolated teachers does not show that important changes have taken place in a school culture. He proposes that in-service training programmes should centre on the school as a whole if visible changes are expected in a school. In some countries - South Africa - short workshops that are organized out of the working environment, have been questioned, because they do not seem to effect the change on teachers' sustained and meaningful professional development (Oswald, 2007).

According to Literature in the field, many countries are involved in inclusive education and in-service training of teachers. For example, Mutepfa and Mpofu (2007), state that the special needs education certification in Zimbabwe is attained after the regular teacher education qualification has been acquired. What is emphasized is inclusive instruction that takes into consideration the needs of all learners, especially those with disabilities. Relating to the in-service training needs of South African teachers to effectively function in inclusive settings, Nel (2007), reveals that the focus is on the following: inclusive education; barrier identification; barrier assessment; support of barriers; support of learners; record keeping; profile compilation; referral procedures; multidisciplinary collaboration; interviewing and the support system. Despite this focus, Reddy cited in Oswald (2007), identifies the following as problems related to in-service teacher training in South Africa: the focus of in-service programmes for teachers still on the deficit model approach; mismatch between what is offered in training and teachers' needs; the training period is short and generally the training is offered in workshop set-up, made up of short durations ignoring both the personal and professional needs of teachers.

\section{Concluding Remarks}

A crucial element in the development of inclusive practice is better preparation of and support for teachers that incorporate the elements outlined above. One way of conceptualizing this task might be to take the lead from Shulman (2004) who talks about the need to ensure that training and induction in all the professions has three essential elements. He refers to these elements as the 'three apprenticeships'. The first is the 'apprenticeship of the head': by this he means the cognitive knowledge and theoretical basis of the profession; the second is the 'apprenticeship of the hand': this would include the technical and practical skills that are required to carry out the essential tasks of the role; and the finally the 'apprenticeship of the heart': the ethical and moral dimensions, the attitudes and beliefs that are crucial to the particular profession and its ways of working. At the heart is the involvement of the staff in the School in developing new approaches to training teachers to ensure that new teachers:

have a greater awareness and understanding of the educational and social problems/issues that can affect children's learning; and

Have developed strategies they can use to support and deal with such difficulties.

Florian (2007) has identified three areas that deserve particular attention in the reform of teacher education based on the argument that future progress in inclusion requires new ways of thinking about provision and practice. These are: clearer thinking about the right to education; the need to challenge 
deterministic views about ability; and a shift in focus from differences between learners, to learning for all. Florian's 'three areas' (educational rights, anti-determinism and learning for all) have been embedded in the course. It is also informed by the principles of learning, participation, collaboration and activism as drivers of teacher professionalism in changing contexts of education that include the multiple overlapping layers of teaching and learning, the community of a school, and the school in the broader social and political context (Sachs, 2003). The over-riding aim is to help new teachers accept the responsibility for the learning of all pupils in their classrooms and to know where to turn for help when required. If this task is to be successful it will entail addressing all three of Shulman's (2004) apprenticeships.

\section{REFERENCES}

[1] Ainscow, M. (1997) Towards inclusive schooling. British Journal of Special Education, 24 (1), 3-6. Ball, S. J. (2006) Education policy and social class: The selected works of Stephen J Ball. London: Routledge. Black

[2] Hawkins, K., Florian, L.\& Rouse, M. (2007) Achievement and inclusion in schools. London: Routledge.

[3] Ellins, J. \& Porter, J. (2005) Departmental differences in attitudes to special educational needs in the secondary school. British Journal of Special Education, 32 (4), 188-195. 1818 European Agency for the Development of Special Needs Education (2006) Inclusive education and classroom practice.

[4] Evans J. \& Lunt I. (2002) Inclusive education: Are there limits? European Journal of Special Needs Education, 17 (1), 1-14.

[5] Florian, L. (2007) Reimagining special education. In L. Florian (ed.). The SAGE handbook of special education. London: Sage. Pp 7-20.

[6] Florian, L. \& Rouse, M. (2001) Inclusive practice in English secondary schools: Lessons learned. Cambridge Journal of Education, 31 (3), 399-412.

[7] Forlin, C. (2004). Promoting inclusivity in Western Australian schools. International Journal of Inclusive Education, 8, 183-200.

[8] Forlin, C. (2001). Inclusion: Identifying potential stressors for regular class teachers. Educational Research, 43 (3), 235-245.

[9] Gillborn, D. \& Youdell, D. (2000) Rationing education: Policy, practice, reform and equity. Buckingham: Open University Press.

[10] Grubb, W. N. \& Lazerson, M. (2004) The education gospel: The economic power of schooling. Cambridge, MA: Harvard University Press.

[11] Hargreaves, L., Cunningham, M, Everton, T., Hansen, A., Hopper, B., MacIntyre, D., Maddock, M., Muckerjee, J., Pell, T., Rouse, M., Turner, P. \& Wilson, L. (2006) The status of teachers and the teaching profession: Views from inside and outside the profession. London: Department for Education and Skills (Research Report RR755).

[12] Kauffman, J. M., Landrum, T.J., Mock, D., Sayeski, B. \& Sayeski, K.S. (2005) Diverse knowledge and skills require a diversity of instructional groups: A position statement. Remedial and Special Education, 26 (1),

[13] 6. McLaughlin, M. \& Rouse, M. (2000) Special education and school reform in the United States and Britain. London: Routledge. Organisation for Economic Development and Cooperation (2005) Students with disabilities, learning difficulties and disadvantages - Statistics and indicators. Paris:

[14] OECD. Organisation for Economic Development and Cooperation (2007) OECD review of quality and equity of education outcomes in Scotland. Paris:

[15] OECD. Rouse, M. (2007) Enhancing effective inclusive practice: Knowing, doing and believing. Kairaranga. Wellington: New Zealand Ministry of Education. Rouse,

[16] M., \& Florian, L. (1997). Inclusive education in the marketplace. International Journal of Inclusive Education, 1 (4), 323-336.

[17] Sachs, J. (2003). The activist teaching profession. Maidenhead: Open University Press. 
[18] SEED (2006) More choices, more chances. Edinburgh: SEED. SEED (2006) Getting it right for every child: Implementation plan. Edinburgh: SEED.

[19] SEED (2004) Education (Additional Support for Learning) (Scotland) Act 2004. Edinburgh: SEED.

[20] Shulman, L.S (2004) The wisdom of practice: Essays on teaching, learning, and learning to teach. San Francisco: Jossey-Bass.

[21] UNESCO (2005) Children out of school: Measuring exclusion from primary education. Montreal: UNESCO Institute for Statistics.

[22] UNICEF (2000) Dakar Framework for Action: Education for all: Meeting our collective commitments. .

\section{AUTHOR's BIOGRAPHY}

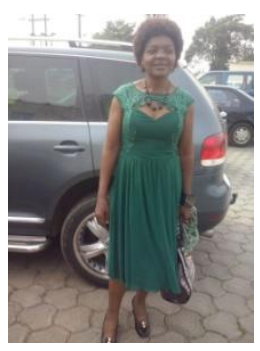

Dr Nchia Mary-Judith Yuoh Epse Mboge, is a teacher of special Needs Education at the University of Buea and Regional Pedagogic Inspector of Secondary Education at the Regional Delegation of Secondary Buea - Cameroon. Nchia Mary-Judith Yuoh has a Ph.D in Special Needs Education with a concentration in Inclusive Education and Learning Disabilities. She has a Master Decree (M.Ed) in Curriculum Development, a Higher Teacher Grade I Diploma (DIPES II) in English Modern Letters and a Bachelor Decree (BA) in English Modern Letters. Among her numerous publications are:

1. Supervision of Instruction in Cameroon: Are Pedagogic Inspectors doing their Work?"

2. Investigating Teachers Attitudes in Inclusive Education: The Case of per sons with learning disabilities

3. Students' Perception of Disabilities in the University of Buea

Dr. Nchia Mary-Judith Yuoh Epse Mboge is a renowned researcher working with: Foundation of Scientific Research, Community Based Rehabilitation and Advocacy on Inclusive Education (FORCAIE - Cameroon). 